\title{
Women Participation in Cotton Farming in Simiyu Region, Tanzania: Undefined Paradoxical Praxis
}

\author{
Chami, Avit. A \\ Department of Economic Studies, the Mwalimu Nyerere Memorial Academy-Zanzibar Campus, Tanzania
}

Copyright $(2018$ by authors, all rights reserved. Authors agree that this article remains permanently open access under the terms of the Creative Commons Attribution License 4.0 International License

\begin{abstract}
Cotton stands as one of the key cash crops in the Tanzanian economy and the second largest agricultural export product with over $70 \%-80 \%$ of it being exported. Despite the widely known merits, significances and challenges of integrating gender equality and equity in economic activities, less remains to be known on actual defined participation and contribution of women in cotton farming in Simiyu region, Tanzania. This paper attempted to reveal the existing paradoxical praxis in the course of establishing women contribution in cotton farming in Simiyu region. Specifically, this paper sought to: (i) assess the level of women participation in cotton farming in Simiyu region (ii) examine factors affecting women participation in cotton farming in Simiyu region (iii) assess the perceived role of women participation in the cotton farming in Simiyu region. The descriptive cross-sectional research design was employed. Simple random sampling technique was used to select a total of 120 respondent households from the selected villages from region's districts namely, Maswa, Meatu, Bariadi, Busega and Itilima. Data were collected using pre-tested and pilot-tested questionnaires, focus group discussions and interviews. Ms-Excel and SPSS 20.0 computer software were used to analyze data. Descriptive statistics were

cotton farming were farming technologies and management ability. Based on the study findings it was plausible to conclude low level of women participation in cotton farming in Simiyu region despite numerous undefined paradoxical praxis prevailing in the women involvement in cotton farming including the fact that women are mostly involved in the cotton farming with little recognition as the cotton plots ownership belongs to men who are the heads of the households. Also, the study concludes that social, economic and institutional as the factors affecting women participation in cotton farming in Simiyu region. The study findings further concluded three main perceived roles of women participation in cotton farming, namely offering steady workforce, influence women empowerment and earning income for enhanced women livelihoods in the area. Finally, the study recommended the need of awareness raising strategies to advocate for the usefulness of women participation and involvement in the cotton farming and other economic activities in the study area. However, deliberate gender empowerment interventions are needed in the area to improve farming technologies, farming and market infrastructures to encourage more women to effectively participate in cotton farming in the study area.
\end{abstract} employed to reveal various parameters in the study. The study findings revealed low level of women participation in cotton farming (23.3\%) compared to the revealed level of male $(76.7 \%)$ of the total households involved in the questionnaire survey; suggesting the presence of less number of women who owns lands in the study area. The revealed paradoxical praxis in the study area entails the fact that women who don't stand as households heads don't own piece of land and the whole process of cotton farming. The study findings imply high prevalence of patriarchy kinship in the study area, since the high number households' heads were male. The study findings revealed community attitude and relationships as the main social factors affecting women participation in cotton farming in Simiyu region while financial resources and infrastructures were the revealed economic factors and the revealed main institutional factors affecting women participation in
Keywords Women Participation, Cotton Farming, Paradoxical Praxis

\section{Introduction}

\subsection{Background Information to the Study}

Agriculture sector is the leading sector in the Tanzanian economy. The sector employs about $75 \%$ of the population of the United Republic of Tanzania (FAO, 2013). According to URT (2013), agriculture is an economic activity accounting for $26.5 \%$ of the shares of domestic product by current prices in Tanzania Mainland. Despite agriculture, which in the past ten years has been 
maintaining a steady growth rate of about $4.2 \%$ annually, makes up a quarter of the URT's gross national domestic product and the source of about 34\% of foreign exchange earnings, still its productivity is among the lowest in Sub-Saharan Africa (FAO, 2013). Low productivity in the agriculture sector is mostly due to over-reliance on unpredictable natural precipitation, use of manual labour to work on the land, the limited use of improved seeds and fertilizer and low-productivity among indigenous animal breeds (ASDS, 2001; FAO, 2013).

Cotton is one of the key cash crops in the Tanzanian economy; others being coffee, tea and tobacco. Cotton stands as the second largest agricultural export product with over $70-80 \%$ of it being exported. It is a crop on which $40 \%$ of the national population, that is, about 18 million people depends on for their daily livelihoods (NBS, 2012). In 2010, cotton was produced in 46 districts out of 121 districts and in 13 regions out of 21 regions of Tanzania and occupied 9\% of all the cultivated land (Mwangulumba, et al., 2010). Apart from low productivity, growth of the cotton sub-sector is affected by poor cotton quality resulting from bad agricultural and ginning practices and quality malpractices experienced at different levels of the value chain. The average productivity of Tanzania cotton today is around $300 \mathrm{~kg} /$ acre of seed cotton, which is only $20 \%$ of its potential productivity. Potentially, cotton productivity in Tanzania can reach 1,500 kg/acre. In recent years, Tanzanian cotton has had poor quality and high contamination (FAO, 2013). However it is widely argued that cotton quality aspect are necessary for future profitability and sustainability of the sector and for the industry to significantly contribute to poverty alleviation of cotton growers.

The fact that the cotton sub-sector is faced by myriad challenges including declined fertilizer and pesticide application and insufficient figures for Tanzanian cotton production estimates (Gibbon, 1999; Ponte, 1998), throughout history cotton production in Tanzania has been faced with several challenges including low productivity, poor cotton quality and a low level of mechanization that has resulted in demoralization of cotton farmers, who started opting for alternative crops such as maize, paddy and tobacco. The cotton farming sector was expected to upgrade and scale up product quality and farming practice/processes from time to time including advocating for adequate workforce (Nsimbila, 2014).

Despite well-planned implementation of numerous interventions by Tanzania Cotton Board in the cotton sub-sector, there are indications that activities implemented so far cannot achieve substantial results/outcomes. The myriad project activities implemented on the ground have not yet shown commensurate results. Mwangulumba, et al., (2010) urges low productivity and the poor growth of the cotton sub-sector going in line with poor cultivation methods and partial engagement of all communities' segments. The cotton sub-sector was further affected by poor cotton quality. Hence hinder price level in the world market. However, little is observable on improvement of cotton production, productivity, quality and marketing particularly at farm level as the cotton farming progress presented in the Figure 1 below.

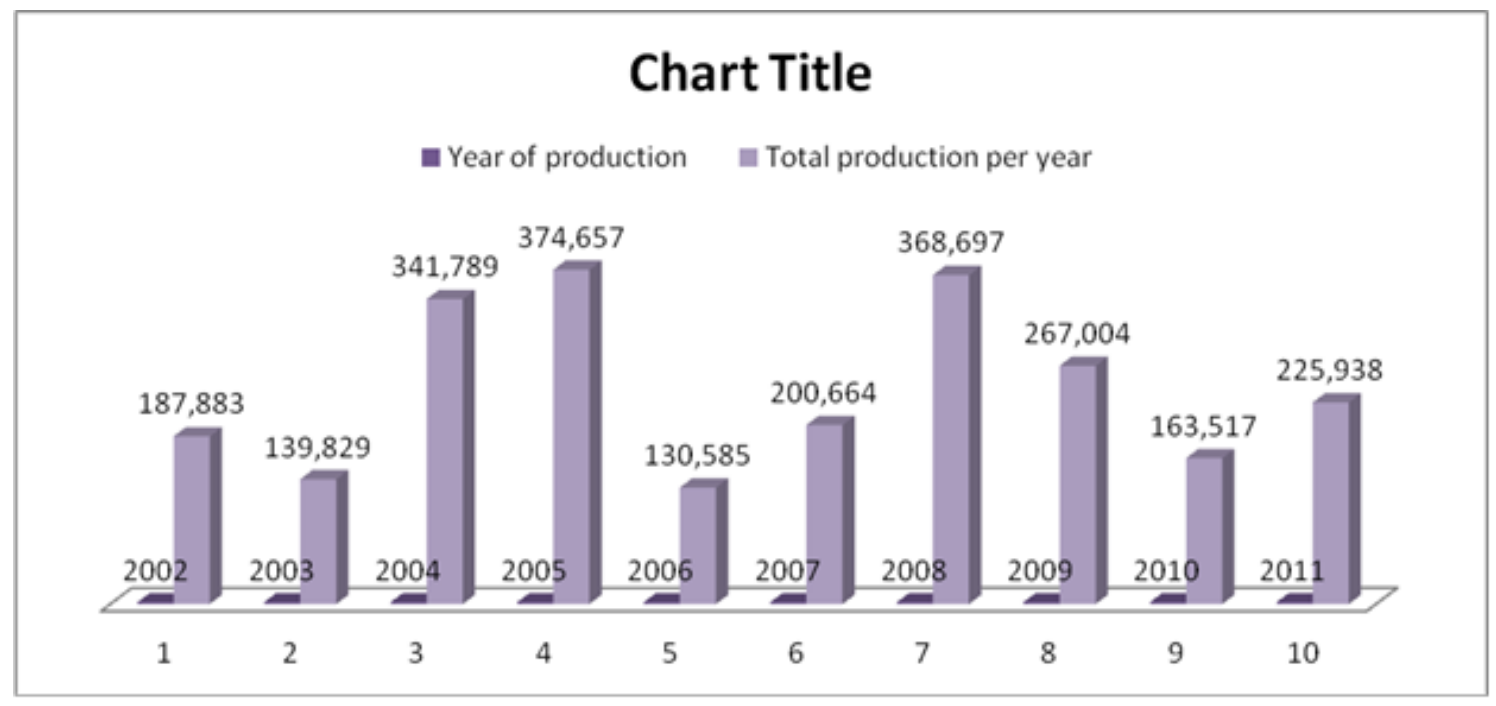

Source: Nsimbila, (2014).

Figure 1. Trend of cotton production in Tanzania from 2002/2003 to 2011/2012 in tonnes 
Following the declining cotton productivity in the country, little remains to be known on the composition of the labour force engaged in the cotton farming with particularly inadequate attention being paid to the level of women participation in cotton farming. The prevailing patriarchy kinship which mostly reflects African traditions as argued by Chami (2016) revealed less number of women participating in various socio-economic activities including environmental conservation, particularly in practicing socio-economic incentives. However, majority of the households in rural areas are traditional patriarchy kinships whereby men are always the heads of the households and women headed households exists if and only if the women are divorced or separated also when the women's husbands have died.

According to Tanzania National Gender Development Policy (2000), the attitudes towards women's capacities to decision-making in Tanzania are changing and more women are being appointed to higher positions of decision-making roles in all levels. Women are still inadequately represented in the decision-making process at all levels, despite affirmative actions taken by the government in the past years. At household level, attitudes still exist that men are automatic heads and breadwinners. These attitudes are based on the patriarchal structures that limit women's voices to be adequately heard and influence the family decisions on resources and other social matters. This among other things substantiates a rationale of underscoring unrevealed paradoxical praxis prevailing in the majority of local rural communities and particularly in the course of evaluating women actual participation and contribution in cotton farming in Simiyu region in Tanzania.

\subsection{Problem Statement and Study Objectives}

The substantial body of literature corroborates the existing wide understanding of the significant merits of equally integrating both men and women in all production activities. It is widely recognized that gender inequality is a major obstacle to socio-economic and political development of any society as it leaves other substantial parts of the community to contribute to the total available workforce production activities. Many studies (Doss and Morris, 2001; Kaaya, Christie and Fuuna, 2007; Kassie et al., 2011) have shown that gender inequality is one of the underlying causes of low productivity as it does, among other things it has been widely argued to hamper the participation of at least half of the country's population in many economic activities. The widely posited significance of gender equality includes its role in availing adequate workforce in the production process.

Despite the widely known merits, significances and challenges of ensuring equality among all people and in particular gender equality and gender equity in any society, less remains to be known on the prevailing undefined women participation and contribution in cotton farming in Simiyu region in Tanzania. This paper was set to investigate paradoxical praxis existing in the women participation and contribution in the cotton farming in Simiyu region in Tanzania. The findings from this paper were envisaged to provide useful inputs for gender specialists, decision and policy makers in the course of enhancing gender mainstreaming in the cotton farming sector. The underscored prevailing undefined paradoxical practices in the area of women participation in cotton farming in Simiyu region are useful in the course of making use of designing effective women empowerment programs which integrates community livelihoods at large. This among others, the findings from this study provides a useful input for scaling-up the available livelihoods options for women in the farming households and communities.

Therefore, the overarching objective of this paper was to assess prevailing undefined paradoxical praxis in the women participation and contribution in the cotton farming in Simiyu region in Tanzania. Specifically, this paper sought to: (i) assess the level of women participation in the cotton farming in Simiyu region (ii) examine the factors affecting women participation in the cotton farming in Simiyu region (iii) assess the perceived role of women participation in the cotton farming in Simiyu region.

\section{Research Methodology}

\subsection{Description of the Study Area}

The study was conducted at the Simiyu Region. Simiyu Region is one of Tanzania's 30 administrative regions. The regional capital is the town of Bariadi. The region was created in March 2012, from part of Shinyanga Region. Simiyu Region is located North of Tanzania and South East of Lake Victoria. The region lies between Latitude 201" and 40 South of Equator and between 3303" and 3501" East of Greenwich. It is bordered by Manyara and Singida Region in the East, Shinyanga Region in the South, Mwanza Region in the West and Mara Region in the North. In the Eastern border and part of Northern lies Serengeti and Ngorongoro National Parks. Administratively, the region has six districts, namely, Maswa, Meatu, Bariadi, Busega and Itilima. The region has 106 Wards and 475 villages.

According to the 2012 national census, the region had a population of 1,584,157. For 2002-2012, the region's 1.8 percent average annual population growth rate was the $23^{\text {rd }}$ highest in the country. It was also the $15^{\text {th }}$ most densely populated region with 63 people per square kilometer. The main indigenous ethnic groups are Sukuma (Nyantuzu), Nyiramba, Nyaturu, Hadzabe (Tindiga) and Taturu. The Sukuma are found almost in all districts in the region, 
Nyaturu and Nyiramba are mostly found in Maswa and Meatu Districts while Hadzabe (Tindiga) and Taturu are mostly found in Meatu District. Despite recent mushrooming activities within the mining industry, agriculture has remained a dominant sector supporting livelihood and economic performance of the region. Crop farming and livestock keeping are the major economic activities in the region. The farming sector contributes about 75 percent to the regional economy and employs about 80 percent of the active population in the region. The main cash crops grown are cotton, groundnuts and sunflower. While the main food crops are maize, sorghum, paddy, sweet potatoes, millet and cassava. Simiyu Region covers a total area of 23,807.7 square kilometers, which is equal to $23,807,700$ hectares. Arable land suitable for agriculture is $11,479,100$ hectares. Total area cultivated is $6,942,378$ hectares which is $60 \%$ of the arable land. Total land which is suitable for irrigation 61,542 hectares and the land which is being utilized according to 2011/12 data is only 14,766 hectares (23.99\%). This land under irrigation is usually planted with paddy, maize and vegetables.

With over 150,000 tons of cotton seeds per annum, Simiyu region is widely recognized as the leading cotton producer in Tanzania. Being the leading region in terms of cotton production, Simiyu region has been a suitable area for investment in cotton ginning, spinning and textile industries. The sector contributes about 75 percent to the regional economy and employs about 80 percent of the active population in the Region. In Simiyu region cotton is mostly grown in Bariadi followed by Maswa and then Meatu. The region has been the leading producers of cotton since it was gazetted by the government to be an independent region (formerly part of Shinyanga). During the two consecutive years $2012 / 2013$ and $2013 / 2014$, the region produced $147,868,265$ and $118,800,544$ tons, respectively. The regional production trends for different regions available in Western Cotton Growing Areas are shown in Figure 2.

From Figure 2, it shows that the former Shinyanga region, which gave birth to currently known Simiyu region, was a leading producer of cotton in the Western Cotton Growing Areas in years prior to 2012. It follows that after Simiyu became an independent region in 2012, the production level for Shinyanga region went down abruptly and that of Simiyu went up. This can be interpreted that most cotton production in the former Shinyanga region was much contributed by districts that had been relocated to Simiyu region. This agrees with data obtained from Shinyanga socio-economic profile.

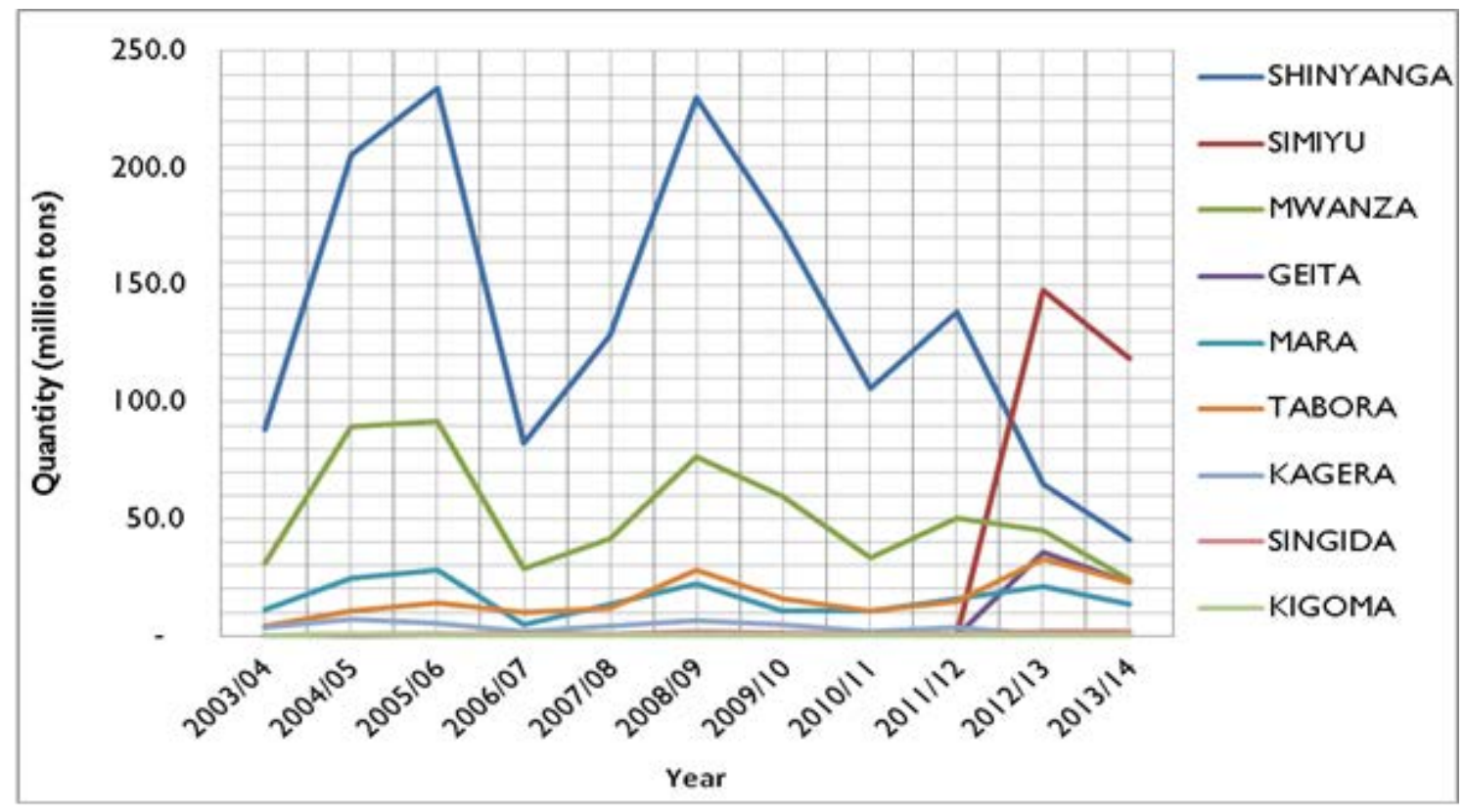

Source: Tanzania Cotton Board, (2014).

Figure 2. Cotton production trends in Western Cotton Growing Areas 


\subsection{Research Design}

This study employed a cross-sectional research design. Under this design, data on the variables of interest were collected more or less simultaneously, examined once, and the relationship between variables determined (Bryman and Bell, 2011). The employed study design was advantageous as it was compatible to the available time and resources.

\subsection{Sampling and Sample Size}

This study was conducted in the four districts of Simiyu region namely Maswa, Meatu, Bariadi and Itilima Districts. The study employed both probability and non-probability sampling methods. Probability sampling method (simple random sampling) was applied to individual cotton producers. As a rule of thumb, 30 respondents were obtained from each of the four villages making a total sample size of 120 respondents. A sample of 120 cotton farmers was approached with both open and closed-ended questionnaires. Non-probability sampling entailed purposive and convenient sampling methods to select key informants (officials who assumedly had the needed information or data pertaining to the study). This made the study easily attain the variables of interest.

\subsection{Data Collection}

Data collection process took place in the four districts in Simiyu region namely Bariadi, Meatu, Maswa and Itilima. Both, primary and secondary data were collected in the course of undertaking this study. Different data collection methods were employed during the conduct of this study including observation, household questionnaire survey, interviews with key farmers and village leaders and literature survey on the cotton farming related documents. Data collection process was conducted in the areas which availed useful information in facilitating the understanding of socio-economic factors affecting women participation in the cotton farming in Simiyu region.

\subsection{Data Processing and Analysis}

After data collection exercise, primary data were checked for completeness before coding, entering and verification for analysis. The filled questionnaires were cleaned to remove all unintended information and were made ready for coding. The coding process resulted to the data entry exercise. The entered data were cleaned to resemble the collected information. Microsoft Excel and Statistical Package for Social Sciences (SPSS 20.0) computer programs were employed for proper housekeeping, arrangement, management and analysis of the collected data. Both content analysis and descriptive statistical analyses were employed to reveal the yet unexplained paradoxical praxis pertaining women participation in the cotton farming in Simiyu region from the collected data. Data analysis for each objective was rigorously performed, presented and discussed in the forthcoming sub-sections.

\section{Results and Discussions}

\subsection{Socio-economic Characteristics of Respondents}

Relevant social-economic characteristics of the 120 respondents who were involved in this study are hereby presented. The social-economic characteristics explored in the pursuit of this study include sex, marital status, and education levels. These are summarized and presented in Table 1. Respondents' characteristics were important in order to provide a snapshot on the background of the respondents and their suitability for this inquiry.

Table 1. Socio-economic characteristics of respondents $(n=120)$

\begin{tabular}{|c|c|c|c|}
\hline \multirow{2}{*}{ Characteristic } & Frequency & Percent \\
\hline \multirow{3}{*}{ Sex } & Male & 93 & 76.7 \\
\cline { 2 - 4 } & Female & 27 & 23.3 \\
\hline \multirow{3}{*}{ Marital Status } & Married & 114 & 95.0 \\
\cline { 2 - 4 } & Single & 6 & 5.0 \\
\cline { 2 - 4 } & Widowed & 0 & 0.0 \\
\hline \multirow{3}{*}{ Education levels } & Non-formal & 51 & 43.3 \\
\cline { 2 - 4 } & Primary school & 48 & 40.0 \\
\cline { 2 - 4 } & Secondary school & 21 & 16.7 \\
\hline
\end{tabular}

Source: Study Findings, (2015).

\subsubsection{Respondents' Sex Distribution}

About $76.7 \%$ of respondents were males and the remaining $23.3 \%$ were females. Directly interpreted, the data show that most of cotton farmers are males. This result is contrary to FAO (2000) finding which asserts that about $70 \%$ of farming activities in Tanzania like in other developing countries all over the world is dominated by women. The finding of $23.3 \%$ of female respondents being cotton farmers revealed a paradoxical and hidden fact that the contribution of women actors in the cotton farming is somehow hidden. Following the fact that the prevailing patriarchy kinship in majority of African communities such that men headed households stands as the ideal household in many communities hence the representative community in Simiyu region suggest less number of women to stand out as households representatives.

\subsubsection{Respondents’ Marital Status}

With respect to marital status the study revealed that; about $95 \%$ of cotton producers were married. The remaining respondents were single, widowed or unmarried at all. This is an indication that cotton farming is highly performed by the households of married couples. It was further revealed that the couples taking place in the cotton 
farming were of young age as it was widely posited that due to inability to join secondary school education, most of villagers resorted to cotton farming as one of their livelihoods activities.

\subsubsection{Respondents’ Education Levels}

The study findings revealed that about $43.3 \%$ of respondents had not attended formal education system while $40 \%$ had acquired primary school education, and only $16.7 \%$ of the respondents who participated in the survey had attained secondary school level. The study interprets that majority of cotton farmers in the study area had attended primary school education or less. With this general education level, the interpretation is that the understanding level amongst cotton producers on technical issues is generally underscored.

\subsection{Level of Women Participation in the Cotton Farming in Simiyu Region}

In the course of revealing undefined paradoxical praxis among women participation and contribution in the cotton farming in Tanzania, it was sought useful to reveal the level of women participation in the cotton farming in Simiyu region. The study findings presented in Figure 2 revealed that only 23. 3\% of the farmers in the study area were female. This implies low level of women participation in the cotton farming in the all four districts of Simiyu Region where the study took place.

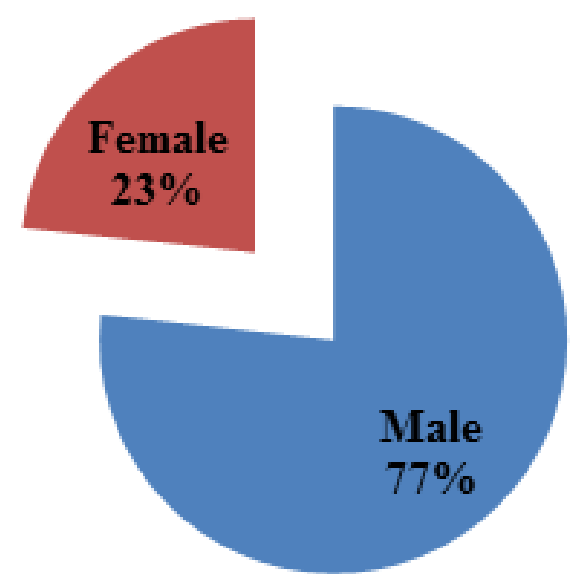

Figure 3. Level of participation in the cotton farming in Simiyu region $(n=120)$

The study findings presented in the Figure 3 imply high prevalence of patriarchy kinship in the study area. This mostly reflects African traditions setting where majority of the households follow patriarchy kinship whereby men are the heads of the households and women headed households exists if and only if the women are divorced or separated, also when the women's husbands have died. Further, the study found that $76.7 \%$ and $23.3 \%$ of the total households are male and female headed households, respectively which suggests the presence of less number of women who owns lands as it is widely supported by Stiglitz (1997) and URT (2013).

However, Njana (2008) depicts usefulness of the sex of household heads towards adaptation of economic empowerment intervention including the enhanced women participation in the cotton farming in the study area. On the other hand, Stiglitz (1997) considered high level of women participation useful towards achieving sustainable development and poverty alleviation through high level of community participation in the economic activities. However the finding is in line with Ockiya (2000) and Adhikari et al. (2003), who found that the presence of majority of both sex i.e. $76.7 \%$ and $23.3 \%$ male and female headed households in the study area, respectively suggests low level of women participation and hence suggests a deliberate interventions for widely integrating women in the socio-economic activities and hence attaining women empowerment through enhanced women participation in cotton farming.

The fact that agriculture sector is the leading sector in the economy of Tanzania as it accounts for about $50 \%$ of the country's GDP and export earnings calls for every capable individual to be engaged. The reported socio-economic development of Tanzania, is highly dependent on the full utilization of its human resource, both women and men. It is widely and undoubtedly realized that the continued marginalization and under-utilization of women who constitute 9.11\% (Population Census 2012) of the population is a major obstacle to rapid socio-economic development of the country. Nonetheless, it is widely known that the potential workforce which almost every household depend is availed by women in the particular household. This lesson was learned from one interview with one key informant in the study area saying:

"It is widely known that women contribute highly to the workforce involved in the entire cotton farming process. They participate from farm preparation level to the harvesting stage. They also play a very important role of educating children and motivate them to get committed in the farm activities during their upbringing since they spent long time in taking care of the family while men spent much of their times in entertaining themselves with local brews in small groceries in the village."

This reality reflects uncounted women contribution in the cotton farming since the farm entitlement and decision making on 'when, what and where to farm' belongs to men. Since the major chunk of cotton farm workforce entail women participants, the accounted participation in the obtained statistics of $23 \%$ female and $77 \%$ male leaves undefined paradox in the mere patriarchy kinship. It is a matter of fact that male counterparts in the households are entitled land ownership rights and household wealth distribution decision-making power. These among others make women lag behind the whole perspective of 
empowerment. This among others suggests deliberate interventions for widely integrating women in the socio-economic activities including farming contrary to the reported $76.7 \%$ and $23.3 \%$ of male and female headed households in the study area.

\subsection{Factors Affecting Women Participation in Cotton Farming in Simiyu Region}

The study sought to reveal the factors affecting women participation in the cotton farming in Simiyu region. The fact that the study findings revealed $76.7 \%$ and $23.3 \%$ of the total households surveyed in the course of pursuing this study being male and female headed households respectively, implying the presence of less number of women who participated in cotton farming, poses a rationale of revealing the factors affecting women participation in cotton farming in Simiyu region. The revealed factors were clustered into three aspects namely social, economic and institutional factors as summarized in the Table 2 .

Table 2. Factors affecting women participation in cotton farming in Simiyu region $(\mathrm{n}=120)$

\begin{tabular}{|c|c|c|c|c|c|}
\hline \multirow{3}{*}{\multicolumn{2}{|c|}{ Challenges }} & \multicolumn{4}{|c|}{ Responses (\%) } \\
\hline & & \multicolumn{2}{|c|}{ YES } & \multicolumn{2}{|c|}{ NO } \\
\hline & & $\mathbf{n}$ & (\%) & $\mathbf{n}$ & $\%$ \\
\hline \multirow{4}{*}{ Social factors } & Attitude & 90 & 75 & 30 & 25 \\
\hline & Preference & 25 & 20.8 & 95 & 79.2 \\
\hline & Relationships & 48 & 40 & 72 & 60 \\
\hline & Education level & 15 & 12.5 & 105 & 87.5 \\
\hline \multirow{3}{*}{ Economic factors } & Financial resources & 86 & 71.6 & 24 & 28.4 \\
\hline & Labour & 36 & 30 & 84 & 70 \\
\hline & Infrastructures & 60 & 50 & 60 & 50 \\
\hline \multirow{4}{*}{$\begin{array}{l}\text { Institutional } \\
\text { factors }\end{array}$} & Policies & 45 & 37.5 & 75 & 62.5 \\
\hline & Technology & 82 & 68.3 & 38 & 31.7 \\
\hline & Training programs & 12 & 10 & 108 & 90 \\
\hline & $\begin{array}{l}\text { Management } \\
\text { ability }\end{array}$ & 85 & 70.8 & 35 & 29.2 \\
\hline
\end{tabular}

Through the surveyed 120 respondents, the factors namely Attitude, Preference, Relationships and Education level were revealed as social factors. Among the social factors which affect women participation in cotton farming in Simiyu region, Attitude was reported by 90 (75\%), Preference was reported by 25 (20.8\%), Relationships was reported by 48 (40\%), and Education level was reported by $15(12.5 \%)$. On the other hand, financial resources, labour and infrastructures were also reported as potential economic factors affecting women participation in cotton farming in Simiyu region. Consequently, the respondents revealed the extent each economic factors affect women participation in cotton farming in Simiyu region such that financial resources was reported by 86 (71.6\%), labour was reported by 36(30\%) and infrastructures was reported by
60(50\%). Further, the study findings revealed Policies, Technology, Training programs and Management ability as institutional factors which affect women participation in cotton farming in Simiyu region. The findings presented in the Table 2 cotton farming technology and management ability were responded by $82(68.3 \%)$ and $85(70.8 \%)$ respectively.

The findings presented in the Table 2 above shows the factors affecting women participation in cotton farming in Simiyu region. Attitude was found to affect women participation in cotton farming as it was reported by $75 \%$ of the respondents involved in the study. The attitude of majority of women towards engaging themselves in the cotton farming activities was found as the key determinant for their participation. The effect of attitude factor was followed by the relationships between women and other members of the households; and the study findings revealed the level and degree of relationships in the particular household could enhance their participation in cotton farming.

On the other hand, the availability of financial resources among women was also revealed as the key determinant of women participation in cotton farming in Simiyu region. This is due to the fact that financial resources could influence the accessibility and availability of farms, farming implements, labour and money for financing other farming operations. This was followed by the quality of agricultural infrastructures as well as its accessibility among many women in the areas where cotton farming is widely practiced. The fact that cotton farming require inputs in terms of farm implements, pesticides and labour which can be taken care by availing all necessary financial resources, infrastructures to facilitate the cause of finishing-up the farming process thereby facilitating the cotton products to reach markets.

The study findings also revealed the management ability among women as a determinant for a good number of women participating in cotton farming in Simiyu region. The fact that majority of respondents (85\%) revealed management ability as one of the factor which is widely affecting women participation in cotton farming in Simiyu region, it was of high usefulness to enhance the women hands-on skills in undertaking farming activities. The management ability factor was followed by the prevailing level of technology endowed by the women towards engaging themselves in cotton farming. The understanding of technology among women enables the women to effectively engage themselves in cotton farming.

\subsection{Roles of Women Participation in the Cotton Farming in Simiyu Region}

The study sought to find out the role of women participation in the cotton farming in Simiyu region. In the course of underscoring potential roles of women participation in the cotton farming in Simiyu region, the 
study shed light on the community's perceptions on the applicable roles played by women in the cotton farming practices. The understanding of local community's perceptions on the roles of women participation in the cotton farming in Simiyu region was important for informing policy makers on the sensitivity of the needs of the particular community. The study results showed three main perceived roles namely offering steady workforce 91(75.8\%), influence women empowerment 19(15.8\%), and earning income $10(8.4 \%)$. The roles were perceived to be very useful in both, influencing cotton farming and supporting women themselves such that the enhanced cotton farming by the increased workforce could lead to increased farm productivity and increased income, which will ultimately improve their livelihood and the community as a whole. The results are presented in Table 3.

Table 3. Perceived roles of women participation in the cotton farming $(\mathrm{n}=120)$

\begin{tabular}{|c|c|c|}
\hline \multirow{2}{*}{ Roles } & \multicolumn{2}{|c|}{ Responses } \\
\cline { 2 - 3 } & $\mathbf{n}$ & $\mathbf{\%}$ \\
\hline Offer steady workforce & 91 & 75.8 \\
\hline Influence women empowerment & 19 & 15.8 \\
\hline Easily adopting new technologies & 10 & 8.4 \\
\hline TOTAL & $\mathbf{1 2 0}$ & $\mathbf{1 0 0 . 0}$ \\
\hline
\end{tabular}

The study findings posit that the perceptions of the roles played by the women through participation in the cotton farming in Simiyu region were mainly on the essence of increasing steady workforce in the course of cotton production. The integration of women in the cotton farming was envisaged of high usefulness since it play dual roles namely improving productivity as it offers steady workforce as well as it enhances women empowerment initiatives and improved community livelihoods. The study revealed $8.4 \%$ of the respondents perceived women participation in cotton farming could mainly make it easy to adopt new farming technologies; it was widely argued in previous studies that; in general women tend to adopt improved technologies at a lower rate compared to men (Doss and Morris, 2001) hence reflecting the findings from Simiyu region.

The study sought to reveal the perceived roles of women participation in the cotton farming in the study area. The findings indicate that majority of the study respondents (75.8\%) widely argued (in favour of) women participation to widely offer steady workforce to the cotton farming. The fact that farming involves high level of labor, the study findings suggest women participation as the major source of farming workforce such that their portion in the population composition in any of remote rural areas populations exceeds that of men. On the other hand women participation influence women empowerment as it bring women into employment opportunities including serving as the labour in different farming processes hence earn income which provide access to basic needs and some of their livelihoods needs.

The study findings further revealed easy adoption of new farming technologies as one of the roles of women participation in the cotton farming since the matter of participating in the cotton farming itself could expose women to the new farming technologies such that they will be in a position to apply the adopted technologies in various income generating activities for sustaining their livelihoods. It is under this circumstance that the study findings urge women participation as the main source of steady workforce and hence envisaged to contribute workforce and resources in the cotton farming in the study area.

\section{Conclusions}

This study was an attempt to reveal the less known dimension of women participation and contribution in cotton farming in Simiyu region. The study concluded that the level of women participation in cotton farming is very low (23.3\%) as compared to the level of male (76.7\%) suggesting the presence of less number of women who owns lands which was used for cotton farming in the study area. The study findings imply high prevalence of patriarchy kinship in the study area. It was also concluded that attitude and relationships among members of the households are the main social factors affecting women participation in cotton farming in Simiyu region whereas financial resources and market infrastructures were the main economic factors; and the main institutional factors were farming technologies and management ability among women. Further, the study findings concluded that three main perceived roles of women involvement in the cotton farming namely offering steady workforce, influence women empowerment and earning income. The study findings imply the perceived women roles to be very useful in influencing cotton farming and supporting women empowerment initiatives as well as the community livelihoods in the region.

\section{Recommendations}

The following recommendations that have been put forward based on the study findings and discussions presented earlier, areas follow:

i The awareness raising strategy should be designed to advocate the usefulness of women participation and involvement in the cotton farming and other economic activities in the study area as the study findings indicate high prevalence of patriarchy kinship in the study area.

ii The deliberate interventions are needed in the area to get farming technologies improved, and production and market infrastructure become user-friendly for women to effectively participate 
and seriously get involved in cotton farming in the study area.

iii There is a need to increasingly capacitating women with training and financial resources to become cotton farmers since it was found to be useful in the own livelihoods and their communities in terms of increasing income.

\section{Acknowledgements}

We are grateful to the Management of the Tanzania Cotton Board for supporting this study as a part of the Tanzania Cotton Board (TCB) assignment through EU-Funded government project, namely, increasing smallholder income through improved quality and market access of cotton produced in Tanzania. We are highly indebted to TCB field technical officers in Maswa, Meatu, Bariadi and Itilima who provided valuable cooperation during data collection process. Our gratitude are also extended to all respondents in the study area but not limited to heads of households, Ward Executive Officers, as well as Village Executive Officers in the study areas.

\section{REFERENCES}

[1] Adhikari, B., Falco, S. D. and Lovett, J. C. (2003). Household characteristics and forest dependency: evidence from common property forest management in Nepal. Ecological Economics 48: pp245-257.

[2] Baffes, J. (2002). Tanzania’s Cotton Sector: Constraints and Challenges in a Global Environment. Africa Region Working Paper Series No. 42, December 2002

[3] Bargawi, H. (2008). The Institutional Challenge in Tanzania's Cotton Sector: Lessons from Southern India, Burkina Faso and From History. Working Paper No. 2008 Swiss National Centre of Competence in Research: May, 2008.

[4] Chami, A.A. (2015). Analysis of potential socio-economic incentives for management of Kondoa Rehabilitated Areas, Dodoma, Tanzania. Masters Dissertation, Sokoine University of Agriculture, Morogoro, Tanzania.

[5] Chami, A.A. (2016). Roles of Socio-Economic Incentives towards Sustainable Environmental Conservation of Kondoa Rehabilitated Rural Areas, Dodoma, Tanzania. Journal of Ecosystem \& Ecography, 6: 210.

[6] Doss, C. R., (2001). “Designing Agricultural Technology for African Women Farmers: Lessons from 25 Years of Experience.” World Development, 29(12), 2075-2092.

[7] Doss, C. R. and Morris, M. L., (2001). "How Does Gender Affect the Adoption of Agricultural Innovations? The Case of Improved Maize Technology in Ghana.” Agricultural Economics 25: 27-39.

[8] EDI. (2004). Rural Shinyanga CWIQ Baseline Survey On
Poverty, Welfare And Services In Rural Shinyanga Districts

[9] FAO. (2013). Analysis of Incentives and Disincentives for Cotton in the United Republic of Tanzania. FAO, Rome, Italy.

[10] FAO. (2013). Review of food and agricultural policies in the United Republic of Tanzania. MAFAP Country Report Series, FAO, Rome, Italy.

[11] ICAC. (2007). International Cotton Advisory Committee Plenary Meeting Report

[12] Kaaya, A., Christie, M. A., and Fuuna, P. (2007). “Gender issues in Aflatoxin Incidence and Control in Peanut Production in Uganda." Summary of Gender Report for Peanut CRSP VT 54.

[13] Kassie, M., Shiferaw, B. and Muricho, G. (2011). "Agricultural Technology, Crop Income, and Poverty Alleviation in Uganda." World Development, 39(10), 1784-1795.

[14] Mwangulumba, E, Kalidushi,B., Kibani, T., Lukonge, E. And Mrosso, F. (2010) Tanzania Country Report On Cotton Research and Production Seacliff Meeting.

[15] Ngailo, J.A., Kaswamila, A.L. and Senkoro, C.J. (2007) Rice Production in the Maswa District, Tanzania and its Contribution to Poverty Alleviation. Research Report No. 07.1. REPOA, 2007

[16] NBS. (2011). Tanzania in Figures, 2010

[17] Njana, M. A. (2008). Arborescent species diversity and stocking in Miombo woodland of Urumwa Forest Reserve and their contribution to livelihoods, Tabora, Tanzania. Dissertation for Award of MSc Sokoine University of Agriculture, Morogoro, Tanzania. 214 pp.

[18] Ockiya, A. J. F. (2000). Socio-economic activities of women in artisanal fisheries of the Niger Delta, Nigeria. Journal of Sustainable Agriculture 1: pp200-205.

[19] Nsimbila, P.M. (2014). The role of contract farming on the productivity of smallholder cotton producers in Bunda district and its effect to other cotton value chain actors in Tanzania. PhD Thesis, Mzumbe University, Morogoro Tanzania.

[20] Tanzania Cotton Board. (2014). Baseline Survey for the project increasing smallholder income through improved quality and market access of cotton produced in Tanzania

[21] Tanzania Cotton Board. (2010). Annual Report and Accounts for the Year Ending on 30th June 2010

[22] RCO. (2013). Simiyu Investment Profile. PMORALG

[23] RCO. (2008). Mwanza Socioeconomic Profile. PMORALG.

[24] Simiyu Region Commission Office. (2013). Simiyu Region Investment Profile.

[25] Stiglitz, J. (1997). An Agenda for Development for the Twenty-First Century. $9^{\text {th }}$ Annual Bank Conference on Development Economics. World Bank, Washington DC. 18pp.

[26] Tanzania Cotton Board. (2010). Second Corporate Strategic 
Plan (2010/2011 - 2012/2013)

[27] United Republic of Tanzania (2013). National Population Census 2012. National Bureau of Statistics, Dar es Salaam, Tanzania. 133pp.
[28] United Republic of Tanzania. (2001). Agricultural Sector Development Strategy, Dar es Salaam Tanzania.

[29] World Bank. (2008). Quality and Marketing of Cotton Lint in Africa; Africa Region Working Paper Series No. 121. 